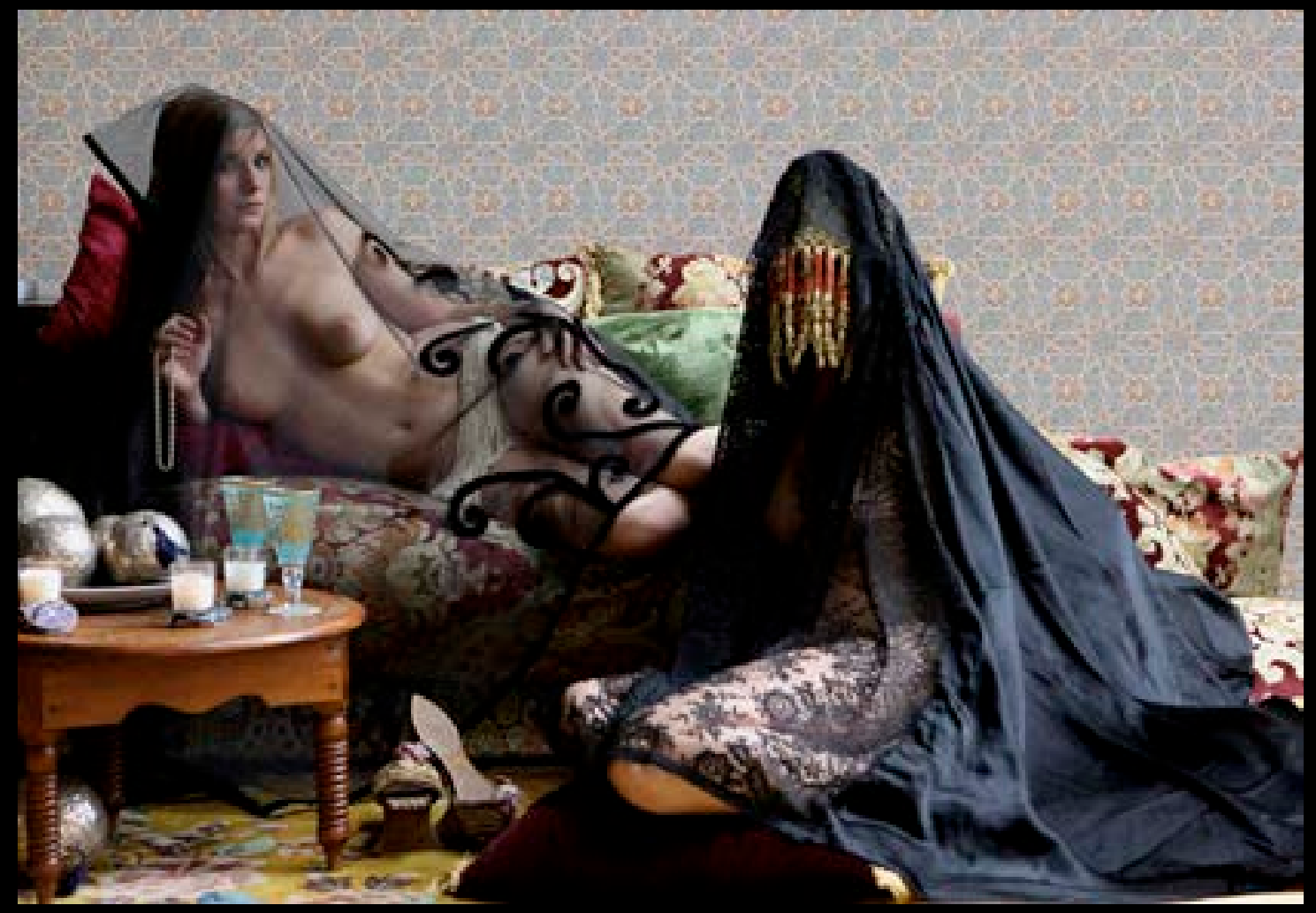


ano 11

n 21

\section{O espaço entre - A fotografia de Majida Khattari}

The space in-between - The Photography of Majida Khattari

A artista marroquina Majida Khattari utiliza a fotografia, as instalações e os desfiles de moda como uma provocação/reflexão sobre o papel do véu no universo muçulmano e no imaginário ocidental. Na série de fotografias denominada Orientalismes, a artista recria os quadros de Delacroix de uma forma subversiva. A relação com a obra do pintor ultrapassa a mera questão temática e pode ser aprofundada. Paul Jamot, ao falar da obra de Delacroix na Documents $\mathrm{n}^{\circ} 5$, de 1930, diz que qualquer tema, nas mãos do artista, converte-se numa forma de revelação e numa visão trágica, tanto nos gestos desesperados de homens em luta, como na aparente lassidão das jovens cativas. $\mathrm{O}$ uso das imagens orientalistas de Delacroix, por Majida Khattari, absorve o sentido trágico e absorve ainda a ideia da imagem como meio de eternizar e universalizar gestos quotidianos. Os véus que, na sua obra, escondem e desvelam, funcionam como mecanismos que tornam visível o que se quer ocultar. Este é o procedimento utilizado nos seus desfilesinstalações, que criam a delimitação de um espaço ambíguo entre eu e o outro. Entre o que se vê e o que se mostra.

keywords:

Majida Khattari; Delacroix; veils; Orientalismes; photpgraphy

Artigo recebido em

27 de março de 2013 e aprovado em 8 de maio de 2013

Majida Khattari, da série Voilée-Dévoilée, 2007-2008.
The Moroccan artist Majida Khattari uses photography, installations and fashion shows as a means of establishing a provocation/reflection on the role of the veil in the Muslim world and in the Western imagination. In the series of photographs called Orientalismes, the artist recreates the paintings of Delacroix in a subversive way. The relationship with Delacroix's work goes beyond the mere thematic issue and can be further developed. Paul Jamot, in speaking about the work of Delacroix in Documents No. 5, 1930, says that any theme in the artist's hands becomes a form of revelation and a tragic vision, both in the desperate gestures of fighting men, as in the apparent looseness of the young captive. The use of Orientalist images in Delacroix, by Majida Khattari, absorbs both the tragic sense and the idea of the image as a means of perpetuating and universalizing everyday gestures. The veils, which in her works hide and reveal, function as mechanisms which make visible what is supposed to be hidden. This is the procedure used in her showsinstallations that create the boundaries of an ambiguous space between the Self and the Other. Between what is seen and what is shown. 


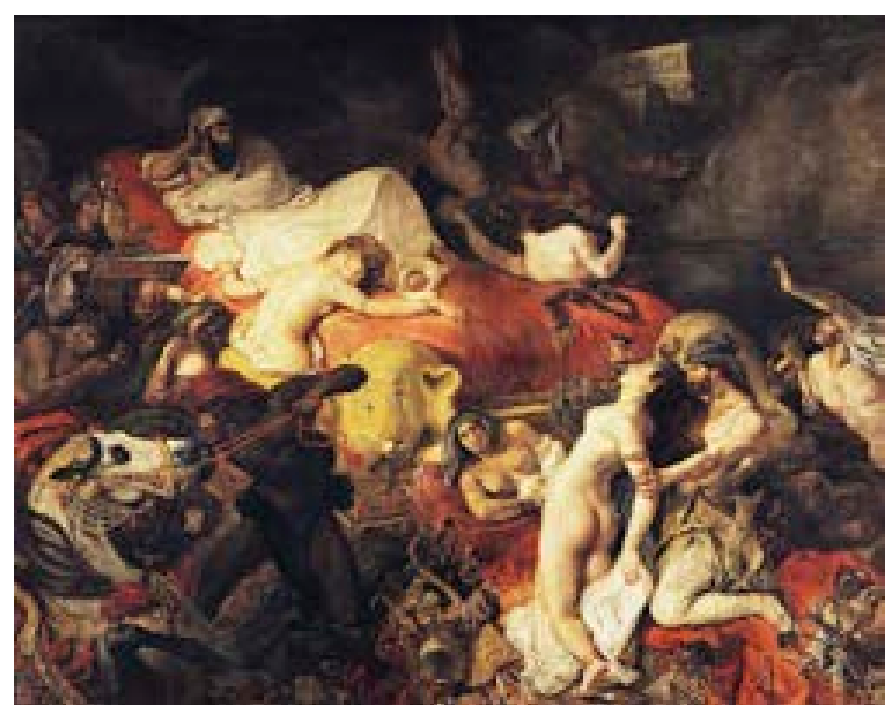

MIRIAN TAVARES

O espaço entre -

A fotografia de

Majida Khattari

Eugène Delacroix, A Morte de Sardanapalo, 1827. Coleção Museu do Louvre

Toute poésie est de circonstance

Eugène Delacroix

Em 1862, o artista neoclássico, discípulo de David, Jean-Auguste Dominique Ingres, pinta o seu Banho Turco. Neste quadro, que reproduz formalmente na tela um olhar voyeurístico, ao negar a superfície retangular e ao dispor a cena dentro de um círculo, reproduz duplamente a visão que o Ocidente tinha então do Oriente: um lugar exótico, sensual e também um lugar inacessível. Só nos era permitido espreitar pelo buraco da fechadura aqueles espaços interditos - o banho turco e a realidade que o envolvia. É interessante observar que Ingres, como discípulo de David, praticou, muitas vezes, um romantismo bastardo, negando seu mestre e concorrendo, diretamente, com Delacroix, o grande nome do romantismo francês.

Delacroix, por sua vez, antes da sua viagem ao norte de África, pintou uma de suas obras mais controversas: A Morte de Sardanapalo. Quadro onde dor e luxúria confundiam-se numa visão excessiva da morte do Rei assírio. Para o artista francês, a pintura não carecia de tema, a tela era uma superfície onde a cor deveria se espraiar e compor formas, mais que motivos. Apesar destas ideias formais, seus quadros, de um modo geral, sempre foram temáticos e muitos com um forte teor político. Mais tarde, aquando da sua viagem à Marrocos e à Argélia, registou em desenhos e pinturas as 
ARS

ano 11

n 21

Jean Auguste Dominique Ingres, Banho Turco, 1863. Coleção Museu do Louvre.

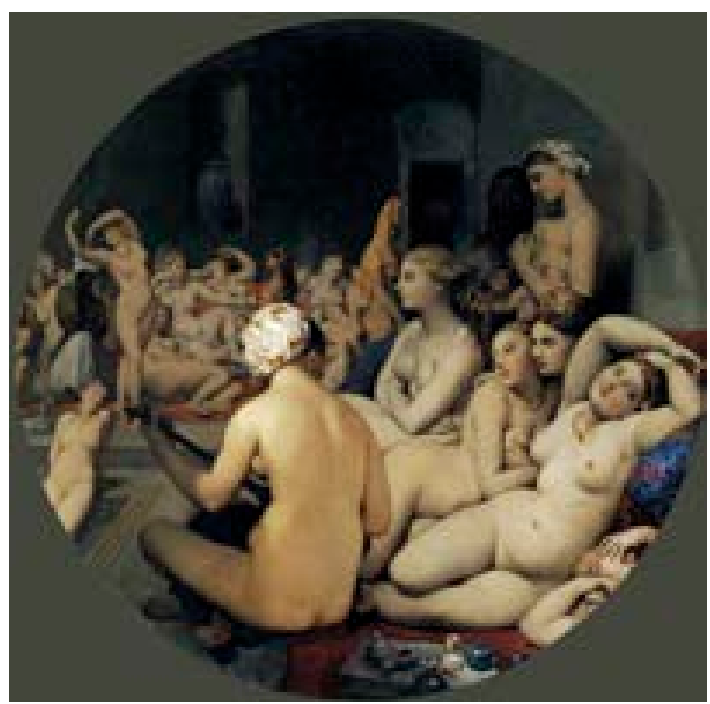

impressões que aqueles países lhe provocaram. $\mathrm{O}$ resultado aproximou-se muito do Banho Turco que Ingres veio a pintar alguns anos depois.

Ingres e Delacroix, de maneira diversa, representam o olhar de uma época sobre uma realidade outra, misteriosa, quase impenetrável, só possível de ser desvelada à distância, ou através de um buraco da fechadura. Com efeito, o problema da visão monocular é que não nos dá uma visão do todo, algo sempre se oculta e a imaginação do artista completa o que não vê. Corpos sensuais e lânguidos, mulheres semi-despidas, algumas encobertas pelo véu que, nos quadros do Delacroix, mais revelam que velam, acicatando o desejo do mundo ocidental.

O Séc. XIX, no mundo árabe, foi marcado pela migração de jovens artistas para países como Itália, França, Espanha e Inglaterra para aprender com os mestres a pintar "à europeia". Exemplos destes trabalhos estão agora a ser exibidos em Paris na exposição Le corps découvert, organizada pelo Instituto do Mundo Árabe. Obras, como a do libanês Georges Daoud Corm, usam o nu como uma recorrência nas suas pinturas, mas o nu é apenas um motivo para desenvolver questões formais e reproduzir os modelos académicos estudados nas aulas das grandes capitais europeias. Da mesma forma que Ingres dizia que gostava de pintar grandes superfícies nuas porque podia trabalhar melhor o desenho e deixar que a pintura deslizasse pela superfície. 
Se para Ingres, e para alguns artistas árabes do final do séc.

\section{MIRIAN TAVARES}

O espaço entre -

A fotografia de Majida Khattari político. Majida Khattari utiliza a fotografia, as instalações e os desfiles de moda como uma provocação/reflexão sobre o papel do véu no universo muçulmano, mas também no imaginário ocidental. O que a artista pretende, com as suas obras, é "perceber a situação ambígua da mulher muçulmana colocada entre sacralização e ameaça.”

Artista e ativista, Majida Khattari reúne, nas suas obras, a moda, a religião e a cultura. Seus trabalhos incluem fotografias, desfiles de moda, instalações e performances cruzando aqui, uma vez mais, diversas fronteiras. Nos seus trabalhos pode ser difícil definir claramente onde começa a fotografia e onde acaba a performance, onde começa a questão formal e onde acaba o discurso. Os suportes escolhidos não são aleatórios, cumprem, rigorosamente, uma função: pôr a dialogar o Ocidente e o Oriente. Mais ainda, pôr em diálogo as visões exóticas que cada um tem do outro e de si mesmo.

A psicanalista Fethi Benslama diz que Khattari "soube lançar uma ponte (passerelle) entre a situação da mulher como desafio político-teológico e a linguagem contemporânea das artes plásticas. (...) uma ponte (passerelle) entre sistema de repressão do corpo da mulher e o sistema da moda.” Uma ponte/passerelle, duplo sentido que se perde na tradução para o português, mas que revela o jogo de palavras presente também na obra da artista: os desfiles de moda são uma ponte entre o passado e o presente, entre o Islão e o Ocidente, entre a roupa que esconde e a roupa que revela.

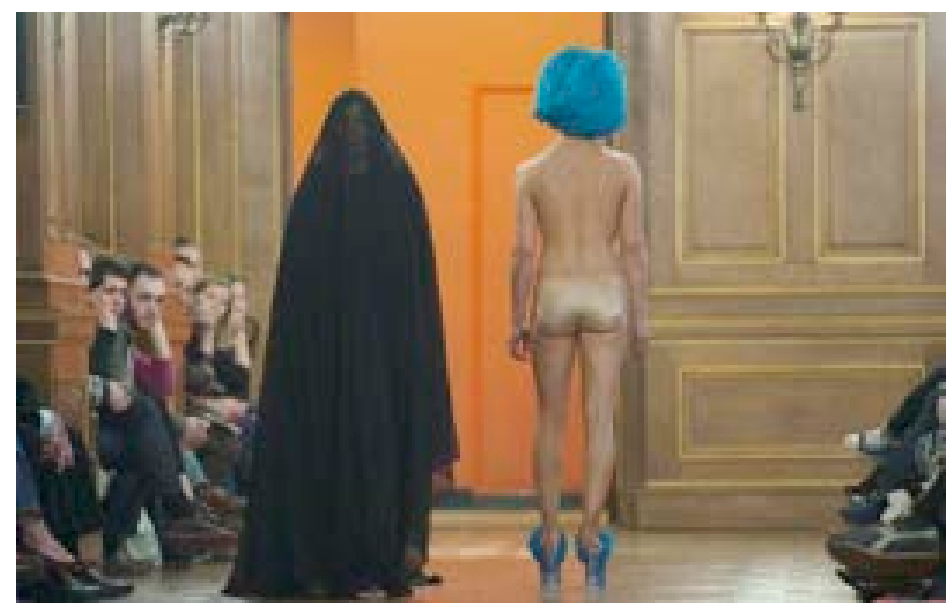

Majida Khattari,

Desfile Performance 4, 2010. Théâtre de la Cité internationale, Paris. 
Na série de fotografias denominada Orientalismes, a artista recria os quadros de Delacroix, subvertendo-os ao substituir as mulheres originais que davam aos quadros o toque oriental por mulheres francesas, em poses semelhantes. A relação com a obra de Delacroix ultrapassa a mera questão temática e pode ser aprofundada ao estudarmos o pintor que foi considerado um dos grandes artistas românticos. Delacroix disse certa vez: "Si l'on entend par romantisme la libre manifestation des ses impressions personelles, non seulement je suis romantique, mais je l'étais a quinze ans." Paul Jamot, ao falar da obra de Delacroix na Documents $\mathrm{n}^{\circ}$ 5, de 1930, diz que qualquer tema, nas mãos do artista, converte-se numa forma de revelação e que ele retrata sempre uma certa visão trágica, tanto nos gestos desesperados de homens em luta, como na aparente lassidão das jovens cativas prosternadas.

O uso das imagens orientalistas de Delacroix, por Majida Khattari, absorve este sentido trágico, para além de questões formais e absorve a ideia da imagem como meio de eternizar e universalizar gestos quotidianos. É necessário que se compreenda o papel que os artistas podem ter no processo de apreensão/criação de imagens. Não há imagens inocentes e muito menos há inocência no discurso por elas construído. $\mathrm{O}$ grande problema das imagens é que elas são, aparentemente, fáceis. Estão ali à espera de alguém que as recolha. Mas é uma falsa aparência porque elas escondem, antes de mais nada, o discurso da ordem, que pode, e em muitos casos deve, ser desconstruído. Os véus que na artista marroquina escondem e desvelam, funcionam como mecanismos que tornam visível o que se pretende ocultar.

Majida Khattari, da série Voilée-Dévoilée, 2007-2008.
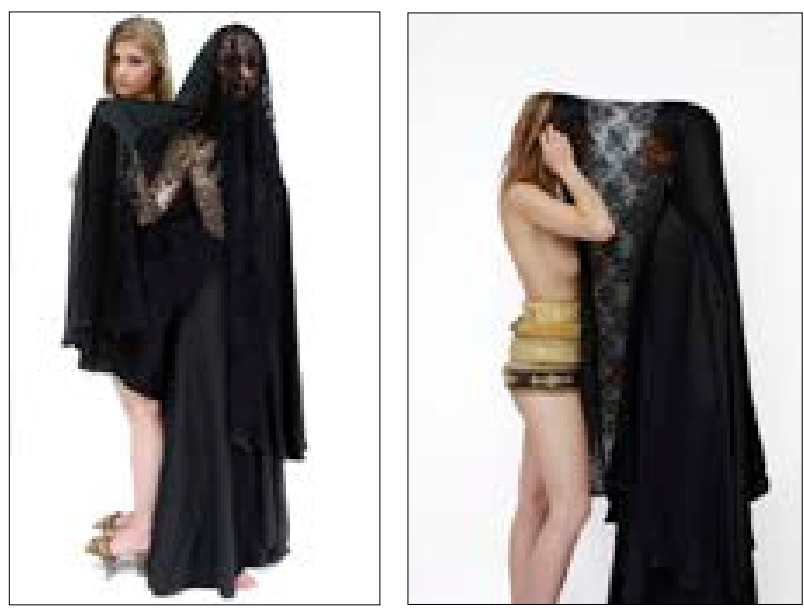
Majida Khattari não quer apenas trazer à superfície duas visões diversas do mundo, mas quer, efetivamente, perceber, através do seu trabalho com a moda, a situação da mulher muçulmana. $O$ recurso ao véu islâmico, segundo as suas palavras, é o pretexto para desafiar a reflexão em A fotografia de Majida Khattari torno dos limites da convivência e dos estereótipos culturais.

Começámos pelo olhar voyeurístico de Ingres porque como ele, o Ocidente não ultrapassou ainda o espaço entre - o interdito. Continua, de modo geral, a espreitar, à soleira da porta, sem compreender muito bem o que vê. Mas, como podemos verificar, este movimento também funciona do lado inverso: criamos imagens sobre o outro que criou imagens sobre nós.

O procedimento que ela utiliza nos seus desfiles-instalações, em que corpos seminus são exibidos ao lado de mulheres com véus-quadros, ajuda a revelar a delimitação do espaço ambíguo entre o eu e o outro. Entre o que vê e o que se mostra. Como disse Georges Bataille, "Malheureusement l'espace est resté voyou et il est difficile d'enumerer ce qu'il engendre”. O espaço, na definição de Bataille, "rompt la continuité de rigueur". E é esta rotura que torna a obra de Majida Khattari um gesto político.

"Na moda, por exemplo, os modelos têm o mesmo corpo e o mesmo olhar, o que constitui, quanto a mim, o mesmo tipo de submissão correspondente à burca. Interessa-me confrontar estes dois tipos similares de condicionalismos, um dos quais é criticado e o outro é aceite como uma evidência natural ", diz a artista. A presença do corpo na arte é uma constante, e a sua nudez ou velamento diz muito do tempo e da cultura que a produz.

A presença do corpo na arte confunde-se com o nascimento daquilo que chamamos de arte, obras que em seu momento tiveram funções diversas, rituais, celebratórias ou mágicas, mas que a história passou a considerá-las como parte do grande acervo artístico mundial. Nem a interdição bíblica à criação de imagens que poderiam confundirse com os ídolos (eídolon) conseguiu refrear o ímpeto dos criadores que continuaram a produzir imagens de si mesmos, retratos idealizados de uma civilização, de uma cultura, de um povo. A arte na contemporaneidade é múltipla e pluridiscursiva: com tantos caminhos abertos, vias, redes, reais e virtuais, com o esboroamento das fronteiras, físicas e simbólicas, parece que ainda não conseguimos falar a mesma língua (estamos todos juntos e muito próximos mas, simultaneamente, terrivelmente distantes). $\mathrm{E}$ a arte reflete sobre isto. 
A escolha da fotografia como medium principal para a produção das suas obras, revela o desejo da artista de trabalhar o papel especular da arte: aquilo que ela revela de nós e aquilo que ela revela para além de nós, o nosso olhar sobre o mundo. Majida Khattari não trabalha com imagens inocentes, usa a arte como uma arma contra a criação dos estereótipos nascidos no seio da própria tradição artística, seja ocidental ou oriental. De tanto olharmos para as imagens de nós mesmo, transformadas pela visão do artista, que reflete uma cultura e um modo de olhar, acreditamos que somos aquilo que vemos. E é esta rotura que a artista pretende provocar: eu sou o que sou e não o que os outros pensam que sabem de mim.

O corpo do artista, ou corpos escolhidos por ele, converteram-se, na contemporaneidade, em territórios onde a questão proposta por Majida Khattari expande-se: a quem pertence o meu corpo? Um corpo identificado num espaço, que já não apenas geográfico e mapeado, é o lugar que define quem sou, o que em mim é meu e o que é fruto de um sentimento comum. $\mathrm{O}$ que me liga aos outros? O que me difere? O que me faz ser eu?

O Mediterrâneo, vários séculos depois, volta a ser um lugar de navegações e trocas, de encontros. Nicolas Bourriaud disse certa vez que a arte contemporânea não é um objeto em si, é a maneira nova de habitar velhos espaços. E são estes velhos e conhecidos espaços, que foram se distanciando, que devem ser novamente visitados e reabitados. Por isso a importância de se pensar hoje numa arte do e no Mediterrâneo. Uma arte com semelhanças e diferenças, com consensos e dissensões, mas uma arte que precisa dialogar mais e absorver melhor o outro, que nunca deixou de ser, apesar da distância, uma outra face de nós mesmos. E é este diálogo que a artista marroquina tenta restabelecer.

Majida Khattari procura, com a sua arte, estabelecer um diálogo entre culturas diversas, entre diversidades dentro da sua própria cultura, entre modos diferentes de se habitar o mundo. Não há um modelo preestabelecido, não há uma fórmula única. Seu trabalho é a afirmação de uma identidade, é a exploração de feridas que foram ocultadas, é, sobretudo, o desejo de ter uma voz.

Por mais diversos que sejam os trabalhos e as técnicas, todos caminham numa direção: o possível diálogo. O possível entendimento que não é a aceitação passiva e pacífica do outro, mas a fusão de ideias e a desejada confusão de identidades e espaços. Navegar já não é preciso. Mesmo sendo necessário. Navegar pode ser a possibilidade de perder- 
se no e com o outro, noutras terras, noutros espaços. Navegar é ir em MIRIAN TAVARES direção $a$. Em direção ao outro, simultaneamente ao passado e ao futuro. Simultaneamente ao Ocidente e ao Oriente.

A artista sabe que o seu trabalho nem sempre atinge os objetivos A fotografia de Majida Khattari por ela pretendidos. Nem sempre o seu discurso é ouvido. Mas tenta, com a sua arte, cumprir uma função: provocar o desassossego e o desejo de saber mais, de prosseguir. Tenta, nas suas performances, desfiles e instalações dar resposta ao desejo, demasiado humano, de confundir-se com o corpo do mundo. E assim realizar a sua vontade, sempiterna, de ser uno.

Mirian Nogueira Tavares é professora Associada da Universidade do Algarve, onde dirige o Mestrado em Comunicação, Cultura e Artes e a Licenciatura em Artes Visuais. Com formação académica nas Ciências da Comunicação, Semiótica e Estudos Culturais (doutorou-se em Comunicação e Cultura Contemporâneas, na Universidade Federal da Baía), tem desenvolvido o seu trabalho de investigação e de produção teórica, em domínios relacionados com o Cinema, a Literatura e outras Artes, bem como nas áreas de estética fílmica e artística. Atualmente coordena o CIAC (Centro de Investigação em Artes e Comunicação).

Majida Khattari, da série Le Louvre Abu Dhabi, 2009. 


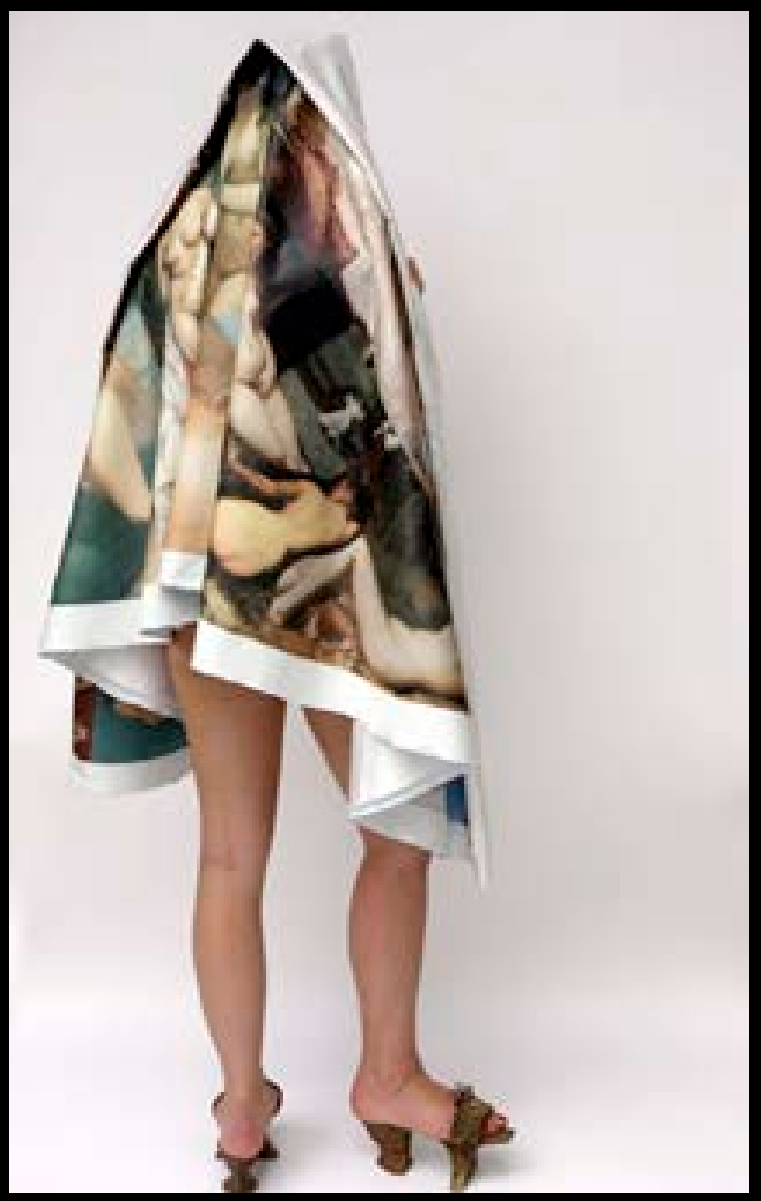

